\title{
DEFENSORÍA UNIVERSITARIA DE LA PONTIFICIA UNIVERSIDAD CATÓLICA DEL PERÚ
}

\author{
Prof. Dra. Catalina Romero \\ Defensora de la Pontificia Universidad Católica del Perú
}

\section{Presentación y antecedentes}

La Pontificia Universidad Católica del Perú es una universidad privada y católica, fundada en el año 1917 por el religioso de los Sagrados Corazones Jorge Dintilhac acompañado por cinco profesionales laicos peruanos. Presento a continuación algunas notas y datos relevantes sobre nuestra Universidad a manera de presentación general.

La universidad se guía y es reconocida por sus valores y el respeto a las normas y derechos que son la base de su sólida institucionalidad. Así mismo toma en cuenta valores humanos y cristianos, como la búsqueda de la justicia, equidad, solidaridad, pluralismo y tolerancia, que ponen en el centro a las personas que forman la comunidad universitaria. Es una universidad autónoma que se gobierna con participación de estudiantes, profesores y autoridades elegidas por los miembros de la Asamblea Universitaria.

Docentes y alumnos, así como egresados han participado en la defensa de los derechos humanos en el país como ciudadanos activos individualmente, en organizaciones de la sociedad civil o como funcionarios en instituciones del Estado como la Defensoría del Pueblo. Un ejemplo de esto es que durante el periodo 2001-2002 el Dr. Salomón Lerner Febres, Rector en ejercicio de la universidad, fue designado como Presidente de la Comisión de la Verdad y Reconciliación por el Gobierno de Transición de Valentín Paniagua y confirmado por el Presidente Alejandro Toledo.

Además de responder a situaciones concretas del país, a demandas de formación de profesionales y de producción de conocimiento y creación de innovaciones, la universidad está creciendo rápidamente, adecuando e innovando su organización para responder a estos cambios, así como creando nuevas instituciones.

En el año 2015, la Pontificia Universidad Católica del Perú, PUCP, tiene 20,707 estudiantes de pre grado, 6,132 estudiantes de posgrado (2015), y más de 50,000 estudiantes de educación continua. Entre el año 2009 y el 2015 el número de estudiantes ha crecido 
$17.5 \%$ en el pregrado, y $24.5 \%$ en el posgrado, siendo explosivo el crecimiento de alumnos en la oferta de educación continua.

Una institución nueva es la Defensoría Universitaria que se creó por iniciativa de un grupo de alumnos y autoridades universitarias, con el apoyo del equipo rectoral. En el Plan de Funcionamiento institucional (aprobado por la Asamblea Universitaria el 19 de diciembre del 2006) se había ya programado crear una Defensoría del Estudiante y evaluar la creación de una Defensoría del Docente pero no se lograba un consenso al respecto en las instancias de toma de decisión, ya que no existía en otras universidades nacionales una institución similar ni era requerida por la Ley Universitaria.

La relación que se estableció con la REDDU, red de defensores universitarios de México, y la CEDU, Conferencia Española de Defensores Universitarios, así como con defensores de Canadá y de Austria, contribuyó mucho a que se entendiera la importancia de contar con una Defensoría Universitaria que atendiera a todos los miembros de la Universidad.

En el 2010 se llevó a cabo una reunión con participación de estudiantes, autoridades universitarias y defensores universitarios invitados y se elaboró la propuesta de creación de la Defensoría Universitaria que se presentó al Consejo Universitario, siendo aprobada en el 2010 y presentada a la Asamblea Universitaria, el órgano máximo de gobierno de la PUCP donde se aprobó en el mes de mayo del 2011.

\section{La Defensoría universitaria}

La Defensoría fue creada por la Asamblea Universitaria el 9 de mayo del 2011 y la primera Defensora Universitaria fue elegida el 16 de marzo del 2012.

En la PUCP, la Defensoría es un órgano autónomo en el ejercicio de sus funciones e independiente de los órganos de gobierno de la universidad, incluido el rectorado. Está encargada de velar por el respeto de todos los miembros de la comunidad universitaria: alumnos, administrativos y docentes.

La Defensoría Universitaria de la PUCP es una de las primeras en crearse junto con la de la Universidad Nacional de Cajamarca, que se creó con anterioridad, pero desde el 2011 hasta el 2013 no estuvo en funcionamiento.

Hasta el año 2014 no existía ninguna norma que regulase las Defensorías Universitarias en el país. Es en ese año que el Congreso promulgó la Ley Universitaria 30220, que rige a las universidades nacionales, en la que se establece, mediante el artículo $133^{\circ}$ que todas las 
universidades (nacionales) deben contar con una Defensoría Universitaria, que se regirá también por el Estatuto de cada universidad. El Estatuto de la Pontificia Universidad Católica del Perú establece en el Título IV, Arts. 100 y 101 las funciones de la Defensoría y los procedimientos de elección y re elección y cese del Defensor Universitario. El Reglamento de la Defensoría Universitaria establece las normas generales para su funcionamiento.

\section{III.El Defensor universitario o la Defensora universitaria}

La Defensora Universitaria o el Defensor Universitario es elegido por la Asamblea Universitaria mediante votación secreta entre una terna de candidatos que es presentada por una comisión conformada por 6 miembros de dicho órgano: un vicerrector (que la preside), tres profesores y dos alumnos. Estos miembros son elegidos por la Asamblea Universitaria. Para ser elegido como Defensor, el candidato debe obtener una votación no menor de los dos tercios del número legal de miembros de la Asamblea Universitaria. Si ninguno de los candidatos consiguiera este número de votos, se realizará una segunda votación únicamente respecto del candidato que haya obtenido la votación más alta. En esta segunda elección, el candidato único deberá alcanzar una votación no menor que los dos tercios de la Asamblea. Si no la obtuviera, la comisión deberá presentar una nueva terna y así sucesivamente hasta lograr la votación requerida.

Las funciones de la Defensora Universitaria o Defensor Universitario se establecen en el Reglamento de la Defensoría Universitaria en el Título II, Art. 5:

Recabar de las distintas instancias o unidades de la Universidad la información que considere oportuna y necesaria para el cumplimiento de sus funciones; b) solicitar la colaboración de las autoridades y funcionarios de cualquier órgano universitario para el desarrollo de sus funciones; c) asistir al Consejo Universitario y a la Asamblea Universitaria cuando fuere requerida su presencia conforme al artículo $87^{\circ}$ del Estatuto de la Universidad. Adicionalmente, puede solicitar su asistencia a la Asamblea Universitaria y al Consejo Universitario en las sesiones en las que se traten materias relacionadas a sus funciones; d) elaborar informes cuando lo considere oportuno; e) efectuar las recomendaciones y propuestas que considere adecuadas para la solución de los casos sometidos a su conocimiento; f) elaborar y presentar anualmente una Memoria de sus actividades en las que se reúnan recomendaciones y propuestas para la mejora de los servicios universitarios y el respeto de derechos en la Universidad; g) proponer acciones para fomentar una cultura de respeto de derechos en la Universidad; h) hacer de conocimiento de la comunidad 
universitaria información concerniente a los temas de su competencia, mediante boletines y otros medios de comunicación de la Universidad.

\section{Asuntos atendidos con mayor frecuencia}

La Defensora ha atendido entre el mes de marzo del 2014 y marzo del 2015 a 52 personas, de las cuales 42 han sido alumnos, 6 administrativos y 4 docentes. Para presentar los asuntos que se suelen presentar a la Defensora con mayor frecuencia me referiré a los tres grupos por separado.

En el grupo de los estudiantes: Uno de los problemas más frecuentes es la evaluación y la disponibilidad de los profesores para recalificar las pruebas y las notas. Éste es seguido por problemas en el proceso de matrícula, que se condiciona a las notas obtenidas que afectan la posibilidad de elección de horarios y profesores, así como alcanzar en vacante en los cursos más solicitados. El otro problema frecuente es la pérdida de permanencia en la universidad que está claramente reglamentada, pero que da lugar a apelación por parte de los estudiantes ante el Decano y el Consejo de la Facultad. Es en estos casos donde se recurre a la Defensoría por consejo o mediación. Otros reclamos menores se relacionan al trato de algunos profesores a los alumnos, seguidos por mala información o información insuficiente en lo que podemos llamar las ventanillas de atención a los estudiantes.

Los docentes no presentan muchas consultas ni quejas, y la mayoría de ellos han estado vinculados a problemas generales en el campus, más que a problemas particulares.

Y en el caso de los administrativos, la Defensora interviene como mediadora entre los trabajadores y la Oficina de Recursos Humanos por motivos de clima laboral, o maltrato a algún trabajador en particular.

En los tres años que me he desempeñado como Defensora Universitaria he recibido 134 consultas y casos que se distribuyen por año en el Gráfico I.

Hay que tener en cuenta que las resoluciones de la Defensora Universitaria en la PUCP no tienen carácter vinculante, por lo que no puede modificar por sí misma acuerdos o resoluciones emanadas de los órganos de la Universidad.

Como hemos dicho, al crearse la Defensoría Universitaria en la PUCP, en el año 2011 no había una legislación estatal que estableciera la creación de esta institución en las universidades peruanas, pero al promulgarse una nueva Ley Universitaria en el 2014 y posiblemente con la referencia de esta Defensoría Universitaria, la única en funcionamiento 
en este momento, se incorpora en la Ley la creación de Defensorías Universitarias en las universidades en el país.

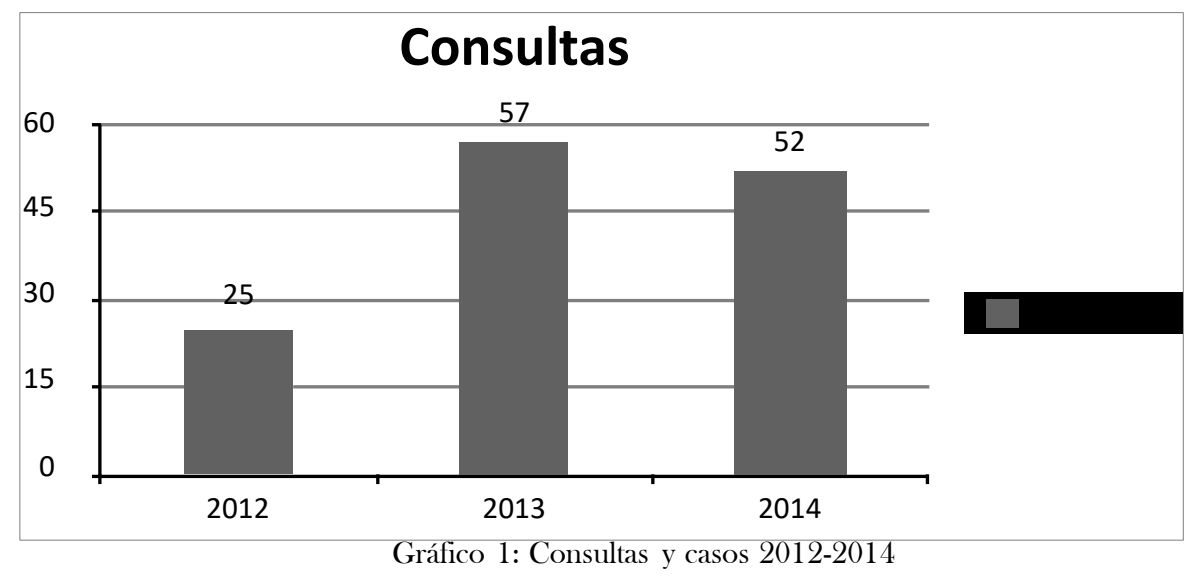

En el plazo que da la Ley se están modificando los estatutos de las Universidades, incluyendo la creación de Defensorías Universitarias, lo que ha llevado a a la Defensora Universitaria de la PUCP a tener contacto tanto con la Universidad Nacional de Cajamarca, que ya ha vuelto a elegir un Defensor Universitario, como con otras universidades interesadas en crear una Defensoría Universitaria para adecuarse a la Ley.

Considerando la reciente promulgación de la Ley Universitaria que incluye a la Defensoría Universitaria y la creciente demanda que se está produciendo de información y formación sobre las funciones y la responsabilidad de esta institución en el medio universitario, y el impacto que puede tener en el respeto a los derechos humanos y universitarios en el país, considero muy importante tener en cuenta la formación de una red de Defensorías Universitarias a nivel nacional, buscando relación sobre todo en el caso de las Universidades nacionales o públicas, con la Defensoría del Pueblo a nivel nacional y regional.

Vinculado a una la oportunidad de establecer redes y contactos a nivel nacional en el Perú, la creación de una red iberoamericana sería muy oportuna para apoyar las iniciativas locales y nacionales.

El contacto que he sostenido como Defensora Universitaria de la PUCP, con la REDDU y el CEDU me ha permitido participar en eventos, intercambiar experiencias y validar las acciones que he venido realizando.

El papel que podrían tener redes nacionales como REDDU o CEDU dependería de su posibilidad de ampliar contactos a otras redes nacionales en América Latina a través de 
visitas, intercambio de publicaciones, y el uso de medios de comunicación digitales que podrían servir como plataforma para ir estableciendo relaciones a nivel internacional.

Esto permitiría plantear un modelo de trabajo en red para las defensorías universitarias en el ámbito nacional, y el respaldo en el ámbito internacional para temas de derechos humanos en las universidades donde se está abriendo camino en los derechos universitarios. Dado que la actuación de los defensores no es vinculante, el respaldo que da la práctica y la casuística generada en las redes de defensores será muy importante para cada defensor en términos de legitimidad de sus propuestas.

Mirando hacia adelante, el intercambio internacional que se ha hecho posible gracias a la iniciativa de la REDDU y el CEDU con la colaboración de los Defensores y las Defensoras de otros países, que han participado en los eventos organizados por ambas redes tendrá que dar un salto proyectándose a una organización más inclusiva y por lo tanto más compleja y nueva. Una red para ofrecer información, abrir espacios de comunicación, ser una red abierta. Una nueva red, requiere de una nueva organización, y por lo tanto será un desafío para todos.

Habrá que preparar los Congresos Iberoamericanos con objetivos comunes, ofrecer diferentes actividades para el mejor intercambio entre países y con temas especializados para tratar en conjunto.

El financiamiento será un desafío, que deberá responder a la organización que deberá ser muy creativa e innovadora, y tendrá que ser enfrentado tanto con actividades desde el equipo central de coordinación, y con aportes de las organizaciones participantes como ha sido hasta ahora. 